\title{
Centralización o descentralización; gestión pública o privada de un "bien escaso": historiografía sobre el agua en la ciudad de México en los siglos XIX y XX
}

\author{
Inmaculada Simón Ruiz
}

Escuela de Estudios Hispano-Americanos, CSIC

Ensayo historiográfico en torno a la gestión del agua en la ciudad de México en los siglos XIX y XX. Se revisan los títulos más significativos desde el Porfiriato a nuestros días, con especial interés en la bibliografía más reciente centrada en la discusión en torno al papel que deben tener el Estado y los gobiernos locales en el control y organización de la distribución de ese líquido tan necesario. Se trata de responder a la pregunta de si el agua debe ser considerada como mercancía o como derecho, utilizando los argumentos de los defensores de una y otra idea.

PALABRAS ClaVE: Agua, centralización, descentralización, poder local, empresa pública, empresa privada, medioambiente.

Essay about the management of the water in Mexico City during XIX and XX centuries. It reviews the most significant titles from the Porfiriato to our days with special interest in the most recent bibliography in the discussion around the paper that must have the State and the local governments in the control of the water. It treats to respond to the question if the water must be considered like merchandise or a human right, using the arguments of the defenders of one and the other idea.

KEYWORDS: Water, centralization, decentralization, local power, private company, public company, environment.

Uno de los países que se encuentra en la actualidad, y que se encontrará en un futuro, con mayores problemas de abastecimiento de agua es México, junto a Estados Unidos, Bolivia, Israel, China e India. ${ }^{1}$ Pero, paradójicamente, no es uno de los que cuente con menos agua por habitante. El

1 Albertani, Claudio: "Globalización y guerras del agua" en http://www.rebelion.org/ docs/7769.doc 
problema no está en la cantidad de este líquido de la que dispone sino en su distribución. En este sentido cabe señalar que no toda la responsabilidad corresponde a la mano del hombre y a la discriminación que hace en el reparto de los bienes. También influyen decisivamente aspectos geográficos. En México, el régimen de aguas es desigual, tanto temporal como espacialmente hablando: sólo llueve durante cuatro meses al año y con mucha mayor intensidad en el sureste mexicano que en el resto del país, pero la mayoría de la población se concentra en el centro, de forma que sólo algo más del $30 \%$ del agua recibida cae en las zonas más densamente pobladas.

Son diferentes los problemas derivados de la escasez de los ocasionados por la abundancia del preciado líquido, pero siempre encontramos casos de mala gestión que vienen a fortalecer las carencias o los excesos de la naturaleza. Así ocurre en la ciudad de México, donde se concentran los dos problemas: por una parte, ha sufrido importantes inundaciones a lo largo de su historia. ${ }^{2}$ Por otro lado, hay una consuetudinaria falta de agua en las colonias o barrios más pobres. Cuando se restableció por primera vez el gobierno local en la capital mexicana en 1998, tras la desaparición de su Ayuntamiento en 1928, el nuevo gobernante, Cuauhtemoc Cárdenas, lanzó un programa cuyo objetivo principal era la mejora de la gestión del agua dentro de un proceso de desarrollo sustentable. Lo primero que tuvo que afrontar fueron las fugas de agua, el mantenimiento de pozos y la necesidad de plantas de tratamiento de aguas residuales para usos distintos del consumo; ninguno de estos aspectos ha sido subsanado en su totalidad hasta el momento.

Uno de los males endémicos que los defensores de la privatización del servicio imputan a la organización del agua en México por parte del gobierno son las bajas tarifas, cuando no el derecho a su acceso de forma prácticamente gratuita como prebenda. Los esfuerzos del gobierno han ido dirigidos en los últimos años a aumentar el precio del suministro, a pesar del gran costo político que esto conlleva. Pero la subida se está llevando a cabo también de manera desigual ya que recae casi en exclusiva sobre los usuarios particulares sin contar que se obtendrían mayores beneficios si el control del pago recayera en los grandes consumidores: la agricultura a gran escala y la industria, que hasta ahora continúan disfrutando de injustifica-

2 Entre otros muchos trabajos, véase Boyer, Richard Everett: La gran inundación: vida y sociedad en México (1629-1638), Secretaría de Educación Pública, México, 1975. 
das subvenciones. ${ }^{3}$ En la ciudad de México, además, son numerosos los asentamientos ilegales en los que residen millones de personas y para quienes el acceso al agua de manera regular no es más que una utopía, entre otras razones porque al no estar registrados como vecinos no se pueden aplicar sobre ellos criterios "económicamente racionales", ya que resulta imposible cobrarles la factura por ese consumo pues no tienen domicilio conocido. Por eso, uno de los más importantes debates que se desarrollan en la actualidad es si el agua debe ser considerada como una necesidad o como un derecho y si es el Estado, en consecuencia, quien debe ocuparse de que el abastecimiento llegue a todos o dejarlo en manos de las leyes del mercado. ${ }^{4}$

Durante la etapa colonial, el agua fue utilizada por el gobierno central para favorecer a sus "amigos políticos" por medio de mercedes y su dominio y distribución estuvo en manos de éstos, a través de la intermediación de la Iglesia y los Cabildos. Desde la Independencia al Porfiriato, las cosas se mantuvieron más o menos de la misma manera si bien hubo tímidos intentos por parte de los Ayuntamientos de introducir mejoras locales, a veces contando con sus propios recursos y otras derivando la gestión a empresas privadas, como veremos más adelante. A lo largo de todo el siglo XIX se puede decir que México sufrió una evolución desigual, pero constante, por centralizar todo el poder en manos del Ejecutivo. En la gestión del agua en concreto, el proceso centralizador tuvo sus inicios con la llegada al poder de Porfirio Díaz y fue en aumento hasta la creación de la Secretaría de Recursos Hidráulicos, que se ocupó del servicio desde los

3 Barkin, David (coord.): La gestión del agua urbana en México, Universidad de Guadalajara, Guadalajara, 2006. Este autor es uno de los impulsores de La Nueva Cultura del Agua en México y defiende su consumo como un derecho humano, así como la importancia de la gestión participativa de este recurso. Ver también del mismo: "La gestión del agua urbana en México", en Balanyá, Belén; Brid, Brennan; Hoedeman, Olivier; Kishimoto, Sakoto y Terhorst, Philipp (editores): Por un modelo público de agua. Triunfo, luchas y sueños, Transnacional Institute, noviembre, 2005. El libro puede consultarse en red en la dirección electrónica del Instituto: http://www.tni.org/detail_page.phtml?\&act_id $=16831$.

4 Shiva, Vandana: Las guerras del agua. Privatización, contaminación y lucro, Siglo XXI, México, 2003. La autora expone que los grandes conflictos por el agua no se desarrollan en torno a las fronteras geográficas sino que son globales y enfrentan a los defensores del líquido como bien ecológico con los que opinan que es un bien de mercado. Sobre este tema ver también el concepto de "soberanía del consumidor" desarrollado por Saunders, Peter: "Citizenship in a Liberal Society", en Turner, Bryan (ed): Citizenship and Social Theory, Sage, Londres, 1993, al que hace referencia Castro, José Esteban: "Agua, democracia y la construcción de la Ciudadanía”, en Varios Autores: La gota de la vida: hacia una gestión sustentable y democrática del agua, Fundación Heinrich Böll, México, 2006. El libro se puede consultar íntegro en www.boell-latinoamerica.org. 
años cuarenta del siglo pasado hasta su desaparición en 1976. Desde entonces se vive el proceso a la inversa: el gobierno central ha "devuelto" el control del agua a los gobiernos locales y a la descentralización se han unido, a partir de 1992, nuevos intentos de gestión privada llevados a cabo con mayor o menor éxito.

La nueva estrategia del agua de Salinas de Gortari (presidente de la República desde 1988 a 1994), dirigida hacia una mayor participación de los usuarios en su gestión, mejora del sistema de abastecimiento y de la calidad y fomento de una nueva cultura del agua con mayor participación de la empresa privada, ${ }^{5}$ coincide con un interés renovado de las Ciencias Sociales por el líquido elemento y su gestión como tema de estudio. Este creciente interés entre los científicos sociales mexicanos ${ }^{6}$ en los años ochenta y noventa viene dado, además, por una tendencia generalizada en

5 Martínez Omaña, María Concepción: La gestión privada de un servicio público. El caso del agua en el Distrito Federal, 1988-1995, Instituto Mora/ Plaza y Valdés, México, 2002.

6 La historiografía sobre el tema es muy antigua en México, si bien en cada época han preocupado más unos aspectos que otros. En el siglo XIX se desarrolló un interesante debate en torno a las obras del desagüe de la Ciudad de México, de las que trataremos más adelante, y que retomó una preocupación colonial que ya se había despertado entre los intelectuales del siglo XVII, cuando comenzaron dichas obras. Alain Musset, en "El siglo de oro del desagüe de México" publicado en Obras hidráulicas en América Colonial, Ministerio de Obra Públicas, Transporte y Medio Ambiente, Madrid, 1993, págs. 53-66, señala que la construcción de dicho desagüe fue motivo de enfrentamiento entre partidarios de utilizar los métodos prehispánicos y los defensores de la construcción del canal de desagüe, que estuvo protagonizado por Enrico Martínez y Adrian Boot. Después de la Revolución primaron los estudios relacionados con el riego y el reparto agrario y en los años 60-70 del siglo XX los estudios relacionados con gestión del agua y conflictividad social. En la actualidad preocupan más los procesos privatizadores y el desarrollo sostenible. La etapa prehispánica cuenta con un interés más antiguo por parte de arqueólogos, antropólogos e historiadores, que buscan en ella modelos exitosos de gestión para estudiar la viabilidad de su aplicación en la época actual o vicios mantenidos con insistencia por apego al pasado, mientras que el tema principal de interés para la época moderna es el del desagüe arriba mencionado porque refleja, además, el conflicto entre la metrópoli, autoerigida en defensora de los intereses de los indígenas, y los habitantes de la capital. En el debate entre Enrico Martínez y Boot subyace dicho enfrentamiento ya que Boot, de origen holandés y calvinista converso al cristianismo, venía nombrado por la Corona, según los defensores de las obras de desagüe, para desprestigiar a los primeros conquistadores y pretendiendo utilizar técnicas indígenas que ya habían demostrado su ineficacia. Sobre las obras públicas en la etapa colonial hay muy buenos trabajos que, si bien no se centran en los aspectos hidráulicos de manera monográfica, sí hacen referencia a las preocupaciones de la época y a la forma de solventarlas como el de Sarabia Viejo, María Justina: Don Luís de Velasco, virrey de Nueva España, 1550-1564, Escuela de Estudios Hispano-Americanos, CSIC, Sevilla, 1978, en el que nos relata el proceso de construcción de la albarrada de los barrios de México y Santiago Tlatelolco y las dificultades para el reclutamiento y manutención de los indígenas, que fue motivo para alimentar la "leyenda negra" en autores como Gage, Thomas: Viajes por la Nueva España y Guatemala, Historia 16, Madrid, 1987; también el de Pazos Pazos, María Luisa: El Ayuntamiento de la Ciudad de México en el siglo XVII. Continuidad y cambio social, Diputación de Sevilla, Sevilla, 1999 y, más específicamente, el de Rojas, Teresa: Nuevas noticias sobre las obras hidráulicas prehispánicas y coloniales en el Valle de México, Instituto Nacional de Antropología e Historia, México, 1974. 
el mundo, motivada tanto por las preocupaciones derivadas del cambio climático como por los procesos privatizadores impulsados por los gobiernos a instancias del Banco Mundial y del Fondo Monetario Internacional.

En el aspecto académico, en México, destaca la labor realizada entre 1993 y 1995 por una serie de investigadores del Centro de Investigaciones y Estudios Superiores en Antropología Social (CIESAS), que, en un convenio con el Instituto Mexicano de Tecnología del Agua (IMTA), realizaron el programa "Historia y Antropología del agua (siglos XIX y XX)", más tarde denominado "Historia de los usos del agua en México (siglos XIX y XX)”. El programa estuvo integrado por Irene Márquez, Diana Birrichaga, Selene López, Blanca Estela Suárez Cortez, Teresa Mora Arias, María del Rayo Campos, Cristina Propios, Isabel Rodríguez, Juan Pablo Rodríguez y Roque Rodríguez, y fue coordinado por Luis Aboites Aguilar, siendo uno de los resultados la publicación del libro de Abortes, Birrichaga, Castañeda y Suárez, ${ }^{7}$ así como una amplia recopilación de material procedente de archivos y bibliotecas nacionales. ${ }^{8}$

Los integrantes del programa señalaron la importancia de rescatar nuevas fuentes para el estudio del agua en la historia de México y desde entonces se han publicado, aparte de la ya mencionada, algunas obras de gran interés. Para avanzar en el conocimiento de este tema en el Valle de México desde la Independencia a las primeras décadas del siglo pasado, el volumen coordinado por Salvador Ávila González ${ }^{9}$ da una idea del tipo de documentación con el que nos podemos encontrar en el Archivo de la Ciudad de México (y dentro de éste en el fondo del Antiguo Ayuntamiento de la capital que es el que se trata en este volumen) para estudiar los conflictos derivados de los usos del agua entre los Ayuntamientos de la ciudad de México y los foráneos (o periféricos) entre la Independencia y 1928, fecha en que se eliminó la institución del Ayuntamiento en la capital mexicana, ya señalada. Como valor añadido, el volumen cuenta con un glosario, muy útil para los que se inician en el tema, así como con un índice temático y una relación de los ramos relacionados con la gestión del agua. Según declaran sus compiladores, el trabajo pretende demostrar la heterogeneidad del fenómeno hidráulico en la región durante el primer siglo de vida inde-

7 Aboites, Luis; Birrichaga, Diana; Castañeda, Rocío, y Suárez, Blanca Estela: Fuentes para la historia de los usos del agua en México (1710-1951), CIESAS/IMTA, México, 1997.

8 Todo ese material se puede consultar en la biblioteca del CIESAS y en la del Archivo Histórico del Agua, ambos en el DF.

9 Ávila González, Salvador: Guía de fuentes documentales para la historia del agua en el Valle de México (1824-1928), CIESAS, México, 1997. 
pendiente y me interesa destacar un rasgo que define al libro, como también al estudio del agua en general: la imposibilidad de separar los temas relacionados con ella para analizarlos en compartimentos estancos. Desde un principio, los autores renunciaron a ordenar la información en bloques temáticos porque "por regla general en un mismo expediente se articulan dos o más variables sobre la cuestión hidráulica" ${ }^{10}$ de manera que se limitaron a organizar la selección de forma cronológica aunque, eso sí, señalando en los descriptores los diversos problemas que se tratan en cada texto.

Lo mismo que el estudio del agua no debe ser entendido como una especialidad en sí misma ya que forma parte de la historia ambiental, de la historia política, de la historia social y, en resumidas cuentas, de todo lo que afecta a la historia del hombre sobre la tierra, tampoco es posible dedicar un estudio únicamente a los conflictos derivados, pongamos por caso, entre vecinos, por el uso de esta o aquella fuente de aprovisionamiento. El problema siempre nos remitirá a otros que tendrán que ver con la legislación, las relaciones de poder entre las instituciones locales y las estatales, el desarrollo tecnológico e, incluso, la historia de la cultura y del significado que una fuente o un caño puedan tener en el imaginario del lugar. Y es precisamente esta diversidad la que ha hecho que su estudio haya ganado tantos adeptos en las últimas décadas porque así como el interés por temas concretos derivados de la gestión del agua nos lleva a otros de carácter general, cuestiones particulares como la historia de la medicina o de los conflictos sociales nos remiten obligatoriamente a investigar sobre el agua.

Hay que señalar también que en dicho interés han tenido mucho que ver las políticas públicas y el esfuerzo de algunas instituciones no sólo científicas sino gubernamentales. El caso de la Comisión Nacional del Agua (CNA) es muy relevante. En 1986 se devolvió a los municipios, al menos en teoría, el control sobre el agua, dando inicio a una nueva etapa, que se caracterizó por la disminución del gasto, el reinicio del cobro sobre los servicios de que hablábamos más arriba y la incorporación de la preocupación ambiental ${ }^{11}$ en el discurso de los responsables políticos. Poco des-

10 Ibídem, pág.13.

11 A esta etapa en la historia de la gestión del agua en México es a la que Luis Aboites denomina "mercantil ambiental", para contraponerla con la etapa del agua nacional que acabó en 1976 con la desaparición de la Secretaría de Recursos Hidráulicos. Aboites, Luis: "Del agua nacional al agua mercantil ambiental. Algunas ideas para hacer investigación sobre historia contemporánea de los usos del agua en México”, en Durán, Juan Manuel; Sánchez, Martín, y Escobar, Antonio (eds.): El agua en la historia de México, Centro Universitario de Ciencias Sociales y Humanidades de la Universidad de Guadalajara/ El Colegio de Michoacán, México, 2005. 
pués, en 1989, se creó la CNA como órgano desconcentrado de la Secretaría de Agricultura y Recursos Hídricos con el fin de que se encargara tanto de la distribución como del control del buen estado de las obras; ${ }^{12}$ la CNA preside desde entonces el Instituto Mexicano de Tecnología del Agua (IMTA).

Dentro de este nuevo discurso estatal en defensa de los recursos y el medio ambiente fue como se desarrolló el convenio entre el CIESAS, el IMTA y la CNA para realizar una tarea de recopilación de fuentes, que fue el programa mencionado. Pero el trabajo no quedó aquí ya que durante la investigación se descubrieron una gran cantidad de documentos dispersos por toda la geografía institucional mexicana que dependían de la CNA y que estaban en pésimas condiciones de conservación. Para solventarlo, se creó en 1997 un archivo dedicado en exclusiva a la historia del agua: el Archivo Histórico del Agua (AHA), ubicado en el centro de la ciudad de México, que cuenta con una amplísima colección de documentos y fotografías ${ }^{13}$ y una importante biblioteca sobre temas hídricos, además de publicar periódicamente el Boletín del Archivo Histórico del Agua, donde se han presentado avances de futuras investigaciones.

En la bibliografía sobre el tema aquí tratado se aprecia que hay un mayor interés, o al menos mayor cantidad de estudios publicados hasta el momento, por la edad contemporánea que por la colonial. No quiere decir esto que no haya buenos e importantes trabajos como los de Alain Musset, ${ }^{14}$ pero quizás debido a que la iniciativa partió de historiadores de los siglos XIX y XX y a que la mayoría de la documentación rescatada en el AHA - que se ha convertido en referente obligado para los investigadores- pertenece a la etapa independiente, son más los trabajos publicados y las tesis centradas en este período histórico. Cada vez más, se nota, sin embargo, un

12 Su vinculación, sin embargo, sigue siendo gubernamental y hubiera sido de desear que se hubiese creado un organismo autónomo. Desde su constitución, la CNA intenta controlar todas las decisiones pero más bien lo que logra es sofocarlas sin que lleguen a ponerse en práctica. Hay que tener en cuenta que hoy en día en México funcionan 2.500 organismos administrativos integrados por personas que, en muchas ocasiones, no tienen la formación suficiente. Además hay 435 sistemas hídricos que funcionan de manera casi autónoma, como señala Brakin, David: "La gestión del agua...", pág. 247.

13 Aunque en principio la mayor parte de la documentación pertenece a finales del siglo XIX - momento en que se produjo el inicio de la centralización en la gestión del agua- y al siglo XX, cuenta también con documentos coloniales y anteriores a la centralización porfirista, si bien la mayoría son copias del original.

14 Musset, Alain: El agua en el Valle de México, siglos XVI-XVIII, 1992; del mismo autor: "El siglo de oro..." y también: "El desagüe evangélico: carmelitas, jesuitas y franciscanos frente a las inundaciones de México (1607-1691)", en Avila García, Patricia (ed.): Agua, cultura y sociedad en México, El Colegio de Michoacán/IMTA, Zamora (Michoacán), 2002. 
interés en el estudio de formas prehispánicas de aprovechamientos de agua y sobre algunas de las obras hidráulicas y de los conflictos derivados del uso de este recurso en la etapa colonial.

En este sentido cabe destacar artículos como el de Pilar Iracheta sobre los conflictos por este producto en la villa de Toluca (XVIII) ${ }^{15}$ o el de Gloria Camacho sobre repartimientos de agua en Atlixco e Izúcar (15501650). ${ }^{16}$ Más innovadores resultan los trabajos de Israel Sandre Osorio sobre la gestión del agua en la época colonial y su continuación en el siglo XX mediante la organización de las Juntas de Agua en el Estado de México. ${ }^{17}$ Tras el auge que tuvieron los estudios centrados en los procesos centralizadores y en los modelos de gestión privada en los años ochenta y noventa, de los que hablaremos más adelante, son muchos los investigadores que tienden a pensar que resulta más interesante estudiar las formas locales de organización en torno al control de agua que insistir en si el gran gestor es el Estado central o el local; o mejor aún, que el estudio de estas formas locales nos dará la clave para saber si realmente el recurso está centralizado y si su buena/mala gestión depende del gobierno o de las asociaciones de usuarios y regantes. Sin duda, este nuevo planteamiento es resultado del coloquio "El agua en la historia. Balances y perspectivas", realizado por el Colegio de Michoacán, el AHA, el CIESAS y la Universidad de Guadalajara. El encuentro contó con la presencia de historiadores, antropólogos y sociólogos y una de las conclusiones fundamentales aportadas por Luis Aboites fue la propuesta de abandonar la clásica idea de la evolución del control sobre el agua como un proceso continuo hacia la centralización. A cambio, considera que es más útil observar el papel de las "diversas y variadas organizaciones locales" como hicieron Rocío Castañeda - que presentó en aquella ocasión una ponencia en torno a los pequeños sistemas de riego entre 1920 y 1940—, e Israel Sandre, con un trabajo sobre las Juntas de Agua en el río Cuautitlán entre 1921 y $1940 .^{18}$

15 Iracheta, P.: "Conflictos por el recurso en la villa de Toluca (XVIII)" en Boletín del Archivo Histórico del Agua, n. $^{\circ} 22,2002$, págs. 4-12.

16 Camacho, Gloria: "Repartimientos de agua en Atlixco e Izúcar (1550-1650)" en Ibídem, n. ${ }^{\circ} 23,2003$, págs. $7-18$.

17 Sandre Osorio, Israel: "Conflictos en torno a la distribución de las aguas del Río Cuautitlán, Estado de México, en la época colonial y en el siglo XX”, Ibídem, n. ${ }^{\circ}$ 25, 2003, págs.18-30, y del mismo autor "Conflicto y gestión del agua. El caso de las juntas de agua en el estado de México (19201950), Ibídem, n. ${ }^{\circ} 26,2004$, págs. 35-44.

18 Muchos de aquellos trabajos fueron publicados en Durán, José Manuel; Sánchez, Martín, y Escobar, Antonio (eds.): El agua en la historia... 
En el caso de estas últimas, Sandre indica que existían juntas de origen colonial y otras organizadas por el Estado. Las primeras no eran gubernamentales, pero a partir de finales del siglo XIX, y sobre todo desde $1915^{19}$ en el Valle de México, o bien fueron designadas directamente por el Gobierno o bien se vieron obligadas a perder su autonomía y a someterse al reconocimiento del poder central para poder ser consideradas legales y tener voz y voto en las cuestiones hídricas. Aunque el autor no se dedica a hacer un análisis exhaustivo de su comportamiento, llega a la conclusión de que, en ambos casos, más allá de su eficacia o ineficacia, un rasgo importante es que con ellas el Gobierno, a través de la Secretaría de Agricultura y Fomento, lograba tener mayor control sobre el uso del agua.

Dentro del estudio de la historia del agua en México, el tema más desarrollado por la historiografía es el del riego. Jacinta Palerm y Tomás Martínez ${ }^{20}$ se han dedicado a su análisis para establecer si México se acerca más al estado despótico, que controla todo el proceso sin dejar intervenir a la sociedad, o al democrático, basado en la participación de los ciudadanos en el tratamiento del agua, y cuál es la mejor opción. Ambos autores coinciden en que en México se complementan el Gobierno central y las pequeñas comunidades de riego. Con demasiada frecuencia el Estado desconoce la realidad a la que se enfrentan los usuarios debido a las transformaciones estacionales de los ríos y al cambio climático, y en este aspecto debe escuchar y atender las solicitudes de los interesados. Pero, por otro lado, también se producen apropiaciones indebidas y desvíos de cursos de agua por parte de los usuarios y es importante que en esos casos el Estado pueda intervenir para evitar abusos e injusticias.

$\mathrm{Al}$ destacar la importancia del estudio de los usos del agua en general, Luis Aboites ${ }^{21}$ no pretende llegar a los límites de la tesis sobre la sociedad hidráulica de Picazo y Lemeunier ${ }^{22}$ para la sociedad mediterránea; tampo-

19 El 6 de enero de 1915 se estableció que tendrían derecho al uso del agua los terratenientes y los campesinos pero también las comunidades que, teóricamente, contaban con ventaja sobre los particulares en caso de pleito. Nótese, por otra parte, que con esta legislación se está reconociendo jurídicamente la existencia de las comunidades indígenas, que debían haber desaparecido mucho tiempo atrás con el triunfo del liberalismo en México.

20 Palerm, Jacinta y Martínez, Tomás (eds.): Antología sobre pequeño riego, 2 vols., Colegio de Postgraduados, México, 2000.

21 Aboites Aguilar, Luis: El agua de la nación. Una historia política de México (1888-1946), CIESAS, México, 1998.

22 Pérez Picazo, María Teresa, y Lemeunier, Guy: "La evolución de los regadíos mediterráneos. El caso de Murcia (siglos XVI-XIX), en VV. AA.: Agriculturas Mediterráneas y Mundo Campesino, Instituto de Estudios Almerienses, Diputación de Almería, Almería, 1994, págs. 15-43. 
co a la del despotismo oriental de Kart Wittfogel..$^{23}$ Más bien quiere aprovechar el análisis de una dimensión social poco atendida para acercarse a problemas históricos globales. Explica que la tesis de Wittfogel argumenta que la relación agua-Estado (en el modelo despótico oriental) es posible, entre otras razones, por la debilidad de la propiedad privada y, sin embargo, en México, el proceso de federalización ${ }^{24}$ en el manejo de este recurso terminó desembocando no en la propiedad estatal sino en la privada como forma primordial de la organización social, incluso a pesar del sistema ejidal postrevolucionario que no puede verse, según su punto de vista, como tendencia antagónica de la propiedad privada.

A lo largo del proceso centralizador, el Estado eliminó a los Ayuntamientos como antiguos interlocutores, mermando su poder económico y político. Con la creación de Juntas de riego, lo que logró fue en no pocos casos reforzar su autonomía, en otros crear pequeños caciquillos - o "aguatenientes", como los denomina Aboites- y todo un aparato burocrático de ingenieros y abogados (nombrados por el Gobierno central) que muchas veces intervenían a favor de los terratenientes en detrimento de las comunidades y los pequeños propietarios; y así, lo que había nacido como un esfuerzo para proteger a los regantes fue, en la práctica, una nueva fuente de conflictos, como señala Israel Sandre..$^{25}$

Dentro de esta evolución centralizadora, interesa ahora hacer referencia al proceso de institucionalización de la ciencia en el México de finales de siglo con respecto al agua, al riego, a su distribución y a las grandes obras hidráulicas que se hicieron en el centro del país. En este proceso, los ingenieros y el capital extranjero tuvieron gran relevancia y, como veremos a continuación, ya hay varios trabajos que se han centrado tanto en el desarrollo institucional como en algunas de las obras públicas llevadas a cabo.

Igual que desde finales del XIX se promovieron las Juntas para el riego, se organizaron otras destinadas a crear obras de ingeniería hidráulica para aprovechamiento de recursos y de canalización y desagüe. Éste es un tema relativamente menos trabajado que el del riego en México. Y dentro

23 Wittfogel, Kart: Despotismo Oriental. Estudio comparativo del poder totalitario, Guadarrama, Madrid, 1966.

24 Utiliza el término federalización para expresar el proceso de apropiación del control sobre el agua por parte del Gobierno central. Según Aboites, el proceso de apropiación de funciones y derechos de ese Gobierno en torno al agua tiene una periodización concreta que va de 1888, cuando por primera vez se legisla a favor del poder central en materia de agua, hasta la fundación de la Secretaría de Recursos Hidráulicos con Miguel Alemán (1946-1952).

25 Sandre Osorio: "Conflicto y gestión...". 
del interés que ha despertado destacamos en la etapa colonial al ya mencionado Musset, y para el Porfiriato, a Perló Cohen y a Hortensia Camacho.

La etapa de construcción de grandes obras hidráulicas fue, sin duda, el período porfirista. Se trata de una época que está muy relacionada con el desarrollo del urbanismo (y, a su vez, con un momento de mayor concentración de la población en las ciudades) pero también con el de la tecnología, que permitió trabajar con materiales modernos y que además exigía nuevas fuentes de energía; con los avances en medicina, que apuntaban al agua como fuente de enfermedades y epidemias; con la centralización, que tendía a dejar sin recursos a los gobiernos locales y, por tanto, sin capacidad de actuación; y con las inyecciones de capital extranjero que venían a contrarrestar la falta de liquidez del Gobierno.

También fue una época, quizás precisamente por las razones arriba mencionadas, en la que se produjo una confianza ciega en los ingenieros como fabricantes de progreso y en su connivencia con políticos locales y empresarios extranjeros y nacionales. No podemos olvidar que el lema del gobierno positivista de Porfirio Díaz fue el de "Orden y Progreso" y que para llevar a cabo su programa ideó todo un sistema de control centralizado y mimó al máximo a los inversores extranjeros que trabajaron codo con codo con los empresarios y los intelectuales mexicanos.

Jiménez Muñoz ${ }^{26}$ señala, para el caso de la capital mexicana, que los padres de la urbanización fueron unos intermediarios a los que denomina portafolieros. Se trataba de aventureros, gente con muchas ideas y con escaso capital que llegaron del extranjero o procedían de las canteras nacionales y que tuvieron que aliarse al capital y entrar en contacto con los poderes locales para poder llevar a cabo sus negocios. Fruto de la iniciativa de estos hombres, la capital mexicana se convirtió en una gran ciudad que contaba con todos los elementos de la modernidad: agua potable, drenaje, electricidad, tranvía...

Paralelamente a estas actuaciones en la ciudad de México, el proceso de centralización se hizo más evidente desde 1903, cuando se estableció que el gobierno político y administrativo allí establecido estaría a cargo del Ejecutivo, con la colaboración de tres funcionarios que dependían de la Secretaría de Estado: el gobernador del DF, el presidente del Consejo

26 Jiménez Muñoz, Jorge: La traza del poder. Historia de la política y los negocios urbanos en el Distrito Federal. De sus orígenes a la desaparición del Ayuntamiento (1824-1928), CODEX Editores, México, 1993. 
Superior de Salubridad y el director general de Obras Públicas, ${ }^{27}$ lo que dejaba al Ayuntamiento prácticamente sin margen de maniobrabilidad si no contaba con la anuencia del Gobierno. El gobernador general era nombrado por el presidente de la República y el presidente municipal por elección indirecta de primer grado. Durante el Porfiriato ambos personajes fueron de la mano y el cargo siempre cayó en Guillermo Landa y Escandón, como gobernador, y en Fernando Pimentel y Fagoaga, como presidente municipal; siendo ambos personajes importantes actores de la urbanización de la ciudad de México junto a José Yves Limantour, los abogados Pablo y Miguel Macedo y Porfirio Díaz, hijo.

Para convertir a México en una ciudad moderna había que introducir grandes cambios en el sistema de drenaje y canalización de las aguas. Desde la conversión de México Tenochtitlan en capital de la Nueva España, la ciudad había sufrido periódicas inundaciones sin que las autoridades hubieran logrado hacer nada definitivo para evitarlas. Recordemos que la antigua capital azteca se erigía sobre un gran lago y que los desplazamientos por ella debían hacerse en gran parte en canoa. Sobre esta superficie lacustre se fueron ampliando los límites de la ciudad sin demasiado control y cuando las lluvias aumentaban, era muy frecuente que el agua siguiera su curso natural y desbordara los límites a que la habían intentado reducir, inundándolo todo.

El gran estudioso de las obras de desagüe en el Distrito Federal durante el siglo XIX es Perló Cohen. ${ }^{28}$ Le interesa particularmente el análisis teórico de las políticas públicas de las grandes obras de infraestructura, además de la descripción del proceso como su inserción en el estudio del Porfiriato. Para ello se centra en tres grandes temas: la explicación de las razones de Porfirio Díaz para llevar a cabo las obras, las condiciones existentes y los medios que las hicieron posibles; analiza el sistema de toma de decisiones procurando desentrañar la lógica de los diversos actores que participaron en las obras y, por último, se fija en el impacto que tuvieron tanto en el sistema hidráulico de la cuenca como en el contexto de la ciudad y del régimen.

Concluye que las obras de desagüe no se emprendieron por motivos económicos, que no fue un grupo o empresa interesada en emprender las

27 Nótese la importancia que se dio entonces a la ingeniería y la medicina y su connivencia con el Gobierno político.

28 Perló Cohen, Manuel: El paradigma porfiriano. Historia del desagüe del Valle de México, Porrúa, México, 1999. 
obras quien insistió para lograr que se llevaran a cabo. Dice que esto lo demuestra el que ninguna de las compañías que participaron en esas obras estaba radicada en México o tenía intereses en la ciudad antes de ser contratada. Y aunque señala que esto no quiere decir que después no se beneficiaran multitud de sectores (entre ellos la banca), se le puede cuestionar que estos beneficiarios, digamos "colaterales", sabían que sería un buen negocio y por eso lo apoyaron desde un principio. Él encuentra, sin embargo, que las razones fueron más bien de tipo político y que don Porfirio las llevó a cabo para "afirmar y justificar la gobernabilidad del poder central sobre la ciudad de México" por un lado, y por otro para "legitimizar y apuntalar su permanencia en el poder". ${ }^{29}$ Y aquí entramos en la clásica discusión entre neoliberales y marxistas en torno a lo público y lo privado, a si es el Estado quien hace las obras públicas o si son éstas quienes lo hacen a él. Más inclinado por la primera opción, Perló señala que todos los gobiernos previos hubieran querido hacer las obras de desagüe porque cada inundación era una fuente de descrédito para el gobierno federal y, sobre todo, para el Ayuntamiento, pero que esos gobiernos no contaron con algo que tuvo Porfirio Díaz: crédito internacional, participación de empresas extranjeras y la creación de la Junta Directiva del Desagüe. ${ }^{30} \mathrm{Y}$ aquí hace una apreciación de gran valor: uno de los aciertos de Díaz, a pesar de su omnipresencia, fue saber delegar ${ }^{31}$ en dicha Junta, lo que agilizó la puesta en marcha al saltarse las complicaciones burocráticas. Más adelante hace una afirmación que hay que sopesar con bastante más precaución al decir que don Porfirio tuvo la voluntad de hacerlo — cosa que, como él mismo había señalado antes, también tuvieron los anteriores gobernantes, si bien no pudieron por diferentes motivos- y además fue constante y se lo tomó casi como algo personal. Más allá de estas apreciaciones basadas en la personalidad del dictador, creo que los argumentos de verdadero peso son el de la confianza depositada en sus subalternos y el crédito internacional.

29 Ibídem...., pág. 293.

30 Que sólo existió mientras duraron las obras. Al terminar éstas se disolvió. Sus miembros pasaron a ocuparse de otros asuntos y no se creó una burocracia alternativa.

31 Dice Leopoldo Zea en El positivismo en México. Nacimiento, apogeo y decadencia, FCE, México, 1968, que "Los Científicos fueron fuertes y poderosos económicamente, porque nunca trataron de disputarle a Díaz el poder político" (pág. 430) y más adelante cita a Calero, Manuel: Un decenio de política mexicana, s.e, Nueva York, 1920, que escribe: "El secreto de la fuerza de los Científicos consistía en aparentar una adhesión sin límite a la política y a la persona del Presidente, para tenerlo así encantusado (sic) y alejar el peligro de perder su apoyo". 
Aunque la decisión de emprender las obras de desagüe no fue tomada por razones de economía sino de política, no pudo ser llevada a cabo hasta que no se contó con el capital suficiente y aquí entra la necesidad de estudiar la capacidad económica de los gobiernos (central-estatal-municipal) para emprender obras de canalización y desagüe y la conveniencia o no de dejar a las empresas que lo hicieran ante la falta de recursos. En este sentido vale la pena destacar el trabajo de Hortensia Camacho, ${ }^{32}$ que demuestra también cómo el Porfiriato fue la época de las grandes obras hidráulicas en San Luis Potosí. Éstas no estuvieron a cargo del presupuesto del municipio debido a la debilidad de sus recursos para emprenderlas y, según ella, ésa fue la razón de que el Estado interviniera en su ejecución. No obstante, Rocío Castañeda ${ }^{33}$ afirma que tampoco el Estado central tenía fondos suficientes y que fue la falta de capital estatal lo que ayudó a que la obra fuera a parar a la empresa privada. Añade que una de las aportaciones del trabajo es demostrar que muchos políticos participaron en esa empresa de manera privada y que esto contribuyó, además, como en el caso de los portafolieros capitalinos, a darles mayor peso político en la zona.

El poder de estos nuevos capitalistas y técnicos se vio reflejado en la composición del propio Ayuntamiento capitalino, donde los ingenieros vinieron a sustituir a los médicos que hasta entonces habían estado en franca mayoría. ${ }^{34}$ Un estudio en profundidad de las relaciones entre urbanismo y política nos desvelaría, sin duda, la misma situación en el resto de las ciudades mexicanas. El acceso a puestos de poder, a veces fue la finalidad y otras el medio para conseguir aumentar las posibilidades de negocio y beneficio, tanto en instituciones locales como en las nacionales.

Es importante señalar que durante el proceso centralizador de Porfirio Díaz también se dieron intervenciones de empresas extranjeras y nacionales que arrendaron los derechos del agua al Gobierno por un tiempo determinado..$^{35}$

32 Camacho, Hortensia: Empresarios e ingenieros en la ciudad de San Luis Potosí: la construcción de la presa de San José, 1869-1903, Editorial Ponciano Arriaga, San Luis Potosí, 2001.

33 Reseña de Rocío Castañeda sobre el libro de Hortensia Camacho en el Boletín del Archivo Histórico del Agua, n. ${ }^{\circ}$ 23, México, 2003, págs. 55-58.

34 Perló Cohen, M.: El paradigma...

35 En la Memoria histórica, técnica y administrativa de las obras del desagüe del Valle de México: 1449-1900, publicada por orden de la Junta Directiva del mismo desagüe, 3 vols. México, 1902, se enumeran todos los contratos que se hicieron con estas compañías y los obstáculos que hubo que vencer. 
Para el caso concreto de la ciudad de México contamos con un debate sobre la oportunidad o no de dejar mano libre a los gobiernos locales y a la iniciativa privada, que ha sido estudiado por Rodríguez Kuri ${ }^{36}$ y por Birrichaga $^{37}$ y que me resisto a no incluir en el texto por lo "contemporáneo" de su contenido. Antes que nada quiero insistir en que durante el Porfiriato, "el gobernador ya no sólo vigilaba y normaba la administración edilicia de la ciudad, sino que ejercía un poder real de decisión sobre un cúmulo de asuntos pequeños y grandes de la capital, de forma paralela o superpuesta al ayuntamiento", ${ }^{38}$ de manera que todas las decisiones debían contar con su aceptación. La organización del gobierno local era colegiada y el Cabildo en pleno se encargaba de los asuntos generales que se leían en el orden del día. Si se consideraba que una cuestión necesitaba mayor dedicación, pasaba a la comisión encargada del tema. El dictamen elaborado por dicha comisión se presentaba en la reunión capitular con posterioridad, para proceder a su aceptación, rechazo o enmienda. En el Porfiriato estas comisiones fueron cerca de veinte, según la época, y entre ellas estaba la del agua, una de las de mayor relevancia junto a las de alumbrado, hacienda y obras públicas, desde 1880. Rodríguez Kuri comenta el debate que se suscitó en el Ayuntamiento en torno a una propuesta realizada por el empresario Carlos Medina Ormaechea para que se le concediera el abasto de agua a la ciudad; la opinión de dos de los regidores, José María Rego y R. Lascurain, fue tajante al definir que, por sus circunstancias particulares, el servicio de agua potable no debía ser considerado un ramo susceptible de otorgar beneficios sino como una obligación de la corporación munici-

36 Rodríguez Kuri, Ariel: La experiencia olvidada. El Ayuntamiento de México: política y gobierno, 1876-1912, Universidad Autónoma Metropolitana Azcapotzalco/ El Colegio de México, México, 1996; del mismo autor: "Gobierno local y empresas de servicios: la experiencia de la ciudad de México en el Porfiriato" en Kutz, Sandra y Connolly, Priscilla (eds.): Ferrocarriles y obras públicas, Instituto Mora, México, 1999, págs. 165-190, donde describe lo que denomina "metacontrato" como el consenso que norma las relaciones entre el Gobierno y los particulares más allá de lo estrictamente legal. En él juegan muchas partes, entre ellas la opinión pública. Dice que en el tema de las relaciones con el poder local, la opinión pública había heredado de la colonia y de la revolución liberal la idea del Ayuntamiento como padre y de su obligación a prestar cierto bienestar a la ciudadanía, que podía exigir que así fuera en caso de sentirse abandonada

37 Birrichaga, Diana: "Las empresas privadas de agua potable en México, 1850-1930", en Suárez Cortez, Blanca Estela: Historia de los usos del agua en México. Oligarquías, Ayuntamientos y empresas en México, 1840-1940, CIESAS/CNA/IMTA, México, 1998, págs.184-225, y de la misma autora: "La empresa de cañerías de Puebla, 1855-1882", en Boletín del Archivo Histórico del Agua, $\mathrm{n}$. o 24, mayo-agosto, 2003, pags.13-21.

38 Ibídem, pág.15. 
pal con la comunidad. Entre los defensores de la privatización estaban los que proponían que la formación de una empresa de agua podía proporcionar otros beneficios paralelos como por ejemplo la creación de fábricas de hilado, de papel y molinos que emplearían las aguas de la compañía como fuerza motriz ${ }^{39}$ Por otra parte, aunque había muchos detractores en torno a las empresas privadas de agua, otros vieron que, ante la falta de recursos de los ayuntamientos para emprender las obras de saneamiento, no quedaba otra opción que dejarlo en sus manos.

Los contratos de concesión de los ayuntamientos a las empresas privadas estipulaban que éstas podían dedicarse al abasto de la ciudad, la agricultura y la industria, indistintamente. Las prerrogativas abarcaban la cesión de bienes de los gobiernos locales, la exención de impuestos sobre los materiales empleados en las obras y la cantidad de agua que cada casa debía recibir, así como el precio por el servicio (cada empresa se comprometía a dar una cantidad determinada, según sus posibilidades: en 1894 la de San Luis estaba obligada a dotar de 300 litros a cada casa, en 1900 la de Monterrey 190 y la de Villahermosa sólo 100). El Ayuntamiento solía reservarse el derecho de regir la empresa, que sólo podía utilizar en beneficio propio el agua que no fuera necesaria para cubrir las necesidades domésticas. Birrichaga da varios datos sobre contratos concretos en diversos lugares de la República y explica que la falta de legislación específica para regular el servicio es lo que hizo posible que cada uno tuviera sus especificidades. Los contratos solían tener cláusulas que permitían el traspaso de la concesión sin necesidad de que intermediara la administración.

Si a finales del siglo XIX hubo mucho interés por las grandes obras hidráulicas y en torno al debate sobre el servicio público o privado, las dos últimas décadas del XX y la primera del XXI han visto renovado ese interés por el agua añadiendo un nuevo punto de vista. Ahora lo que prevalece en el discurso político no es el progreso reflejado a través del urbanismo y de la industria, sino el reparto equitativo de un bien que se está presentando como escaso cuando el mayor problema no reside en su escasez sino en

39 Dentro del discurso progresista de la época y de admiración hacia el extranjero encontramos la obra de Herrera y Lasso que analiza favorablemente la política de irrigación promovida por el gobierno, ya que piensa que traerán gran prosperidad tanto a la agricultura como a la generación de energía y de ahí su esfuerzo en defender que el agua fuera controlada por el Estado, apareciendo los derechos de este recurso como de interés público. 
lo desigual de su distribución ${ }^{40}$ y en la falta de medidas destinadas a conservar, reciclar y aumentar los niveles de agua. En este sentido, los defensores de la privatización y los de la descentralización de la gestión de este recurso se han visto beneficiados por la "cultura de la escasez" para justificar la necesidad de mejorar su gestión y aunque en la teoría se pretende no abandonar a los que tienen menos recursos, en la práctica no parece haber manera de combinar privatización con equidad.

Por esta razón en los últimos años se han realizado varios estudios dedicados a los casos de gestión privada del agua con el fin de reconocer si fueron o no exitosos y por qué. Destacan los trabajos ya mencionados de Birrichaga, ${ }^{41}$ en los que estudia a las empresas dedicadas al agua potable en México no por su interés empresarial sino por su relación con el conjunto de innovaciones tecnológicas relativas a la higiene pública. ${ }^{42}$ La autora sostiene que, a pesar de que aún queda mucho por estudiar, teniendo en cuenta los casos trabajados todo apunta a que, en general, tras los tímidos intentos por privatizar el servicio, los ayuntamientos se dieron cuenta de que esa no era la solución sino que, al contrario, podían aumentar las dificultades. Algunas empresas fueron incapaces de cumplir con lo estipulado en los

40 Antón, Danilo: "Saciando la sed planetaria: los problemas del agua en el fin del milenio", en Ávila García, Patricia: Agua, medio ambiente y desarrollo en el siglo XXI, El Colegio de Michoacán/Secretaría de Urbanismo y Medio Ambiente/Instituto Mexicano de Tecnología del Agua, México, 2003, págs. 15-28. Mientras que la Organización de Naciones Unidas establece que se puede hablar de escasez y de grave crisis de agua en países donde la disponibilidad sea menor de mil metros cúbicos por habitante al año, en México, señala David Barkin, existe un agudo contraste entre el desarrollo y la disponibilidad del agua: aunque el promedio nacional es de 4,811 metros cúbicos por habitante, en las zonas centro y norte del país esta disponibilidad se reduce a 2,044 metros cúbicos por habitante por año, en tanto que en el sureste, la disponibilidad es de 14,294 metros cúbicos por habitante en ese mismo lapso de tiempo. Los problemas no son tanto de disponibilidad como de falta de infraestructuras porque, como señala el mismo autor, los estados de Chiapas, Guerrero y Oaxaca son los que menor acceso a agua potable y saneamiento tienen. Barkin, David: "Escasez y contaminación del agua en México: un problema de seguridad nacional. Documento metodológico", http://www.convergenciamexico.org.mx/metagua.pdf.

41 Birrichaga: "Las empresas privadas..." y también, "La empresa de cañerías...".

42 Koch descubrió el vibrio del cólera en 1883; en 1880 Eberth había aislado el bacilo del tifus y poco después Gaffky demostró que ése era el causante de la enfermedad. Como señala Navarro, J. Raúl: "Agua y enfermedad en el Aljarafe durante la crisis del sistema de abastecimiento clásico (19001950)", en Navarro García, J. Raúl y Regalado Santillán, Jorge: El debate del agua en Jalisco y Andalucía, Junta de Andalucía, Sevilla, 2006, págs. 95-152, "el agua era uno de los principales medios de transmisión de la enfermedad pero también era la base de la limpieza y del aseo que debía cortar su expansión...Esta conexión tan íntima entre higiene y prevención fue algo que se hizo más que evidente a lo largo de todo el siglo XIX y también la relación entre abastecimiento de agua y mejora de las condiciones higiénicas" (págs. 100-101). 
contratos y perdieron las concesiones. Tras la Revolución, las empresas privadas encontraron aún más obstáculos porque el Gobierno federal se fue apoderando de los usos del agua y legislando al respecto y muchas veces el propio gobierno terminó comprándolas.

Si bien Birrichaga no se siente capaz de aventurar conclusiones definitivas, sí se anima a abrir nueva líneas de investigación en torno a cómo fueron asimilados por los diferentes actores sociales los cambios científicos y tecnológicos en torno al agua; también propone estudiar comparativamente el servicio público y el privado en diferentes ciudades; otras líneas serían el análisis de las asociaciones de usuarios y su relación con diferentes tipos de demandas. Para el caso poblano, donde se dio el primer intento privatizador del servicio en el siglo XIX, destinado a evitar el control sobre el agua de los antiguos mercedados frente a los vecinos, no se logró cambiar del todo ya que enfrentó serias dificultades como la coexistencia de dos sistemas paralelos de distribución de agua (en línea y en red), la resistencia de los mercedados a pagar las cuotas (a pesar de que las suyas eran más bajas que las del resto de usuarios) y la falta de capital para las obras necesarias.

Sus conclusiones se unen, entonces, a las de Aboites: el tema de conflicto no es tanto si el servicio debe ser público o privado como el de la importancia del comportamiento de los actores involucrados en su gestión.

Como señalábamos más arriba, este interés es más reciente en la bibliografía. A este respecto, Aboites se pregunta que si el proceso "federalizador" ${ }^{\prime 3}$ fue tan caro socialmente hablando, ¿ocurrirá igual con el proceso inverso?, ¿se traducirá la debilitación del poder central en el fortalecimiento de unos poderes locales más despóticos aún? En este sentido, continúa, no hay que olvidar que el proceso de centralización-federalización respondió en cierta medida a la solicitud de algunos núcleos sociales que demandaban un poder mediador que controlara el poder de los terratenientes y los poderes públicos locales. ${ }^{44}$

Otra cuestión a tener en cuenta en el estudio de la gestión del agua en la ciudad de México es que se trata de un proceso cambiante y que en ningún caso se ha dado una gestión privada o pública en su totalidad. Son más bien puntuales los casos en los que se ha dejado el servicio en manos

43 Utiliza el término para explicar lo que entendemos como centralización y lo entrecomilla para señalarnos que fue utilizado bajo esa acepción por políticos e intelectuales decimonónicos.

44 Aboites Aguilar, L.: El agua de la nación... 
de empresas privadas. David Barkin menciona sólo tres: Aguascalientes y Cancún en 1993 y Ciudad de México, donde la legislatura local se reservó la decisión de establecer las cuotas a los usuarios. También nos habla de los pocos casos en los que se ha llevado una descentralización absoluta, como el de León (Guanajuato). ${ }^{45}$ Su trabajo nos lleva a la conclusión de la necesidad de hacer un estudio detallado de la evolución del servicio de abastecimiento y de tratamiento de residuos para intentar responder a qué parte de la responsabilidad corresponde a lo público y qué parte a lo privado y a cuáles son las razones que llevan a uno y a otro a unirse en ciertas ocasiones para saber, en definitiva, si lo que se busca es la obtención de un buen servicio para los ciudadanos o la de un buen negocio o una buena propaganda política y dónde están los obstáculos que impiden la gestión eficaz.

En relación a los servicios públicos la discusión ya no está tanto en privatización/gestión estatal sino en la calidad de los servicios: el problema prioritario no es quién va a gestionar el servicio, sino si con ello va a asegurar que llegue a todos y lo haga de forma equitativa. No podemos dejar de mencionar que estamos hablando de un país en desarrollo y de una ciudad desbordada y en continuo estado de crecimiento.

De nada sirve descentralizar si no se otorgan a los gobiernos locales los instrumentos necesarios para poder ofrecer un buen servicio y si no se concede a los ciudadanos un control sobre los mismos. De nada sirve privatizar si la nueva empresa se va a regir únicamente por criterios económicos, porque el servicio mejorará pero sólo para unos pocos y empeorará para muchos. En ambos casos - descentralización sin recursos y privatización sin restricciones ni control—, sólo "gana" el gobierno de turno al eludir su responsabilidad y, por supuesto, los nuevos gestores públicos/privados con su medro personal. A largo plazo pierde, incluso, el Estado porque se va socavando su confianza en él ya que a través de las privatizaciones “...del papel de proveedor y distribuidor de bienes y servicios públicos, el Estado se convierte en ayudador, promotor y regulador de las acciones de la iniciativa privada". ${ }^{46}$

En México las privatizaciones se están llevando a cabo dentro de un marco político de adelgazamiento del Estado que resulta especialmente negativo ya que la ciudadanía está aún por definir y el estado del bienestar

45 Barkin: "La gestión del agua...."

46 Martínez Omaña, M. C.: La gestión privada..., pág. 29. 
jamás llegó a ser una realidad. ${ }^{47}$ Por otra parte, se están gestionando dentro de un esquema económico interno en el que se repite el aumento de la demanda debido al crecimiento de la población urbana y es una constante la ineficacia y los déficits permanentes de las empresas estatales.

De ahí el interés despertado en la Ciencias Sociales y la necesidad de que todos - científicos sociales, actores políticos, ciudadanos y empresarios- aunemos nuestras fuerzas para evitar que el proceso continúe sin control. De ahí también que, sin dejar de tener en cuenta que debemos cuidar el agua que consumimos y nuestro entorno, procuremos huir de los discursos apocalípticos que muchas veces, incluso de manera inconsciente, están viniendo a servir a los intereses particulares.

Recibido el 4 de septiembre de 2007 Aceptado el 29 de octubre 2007

47 En ciudades como México, Distrito Federal no puede decirse que la globalización y las privatizaciones sean las únicas responsables de su deterioro pero sí que las políticas neoliberales han venido a contribuir a dificultar aún más las cosas. Ziccardi, Alicia: "Gobiernos locales: entre la globalización y la ciudadanía (reflexiones sobre las transformaciones recientes en el Distrito Federal)" en Desarrollo Regional y Urbano (tendencias y alternativas), tomo I, coordinado por el Dr. José Luis Calva, Seminario Nacional sobre Alternativas para la Economía Mexicana, Instituto de Geografía, UNAM, Juan Pablos Editor, México, 1995, págs. 145-162. 